\title{
Community-physician-based versus hospital-based antenatal care: A comparison of patient satisfaction
}

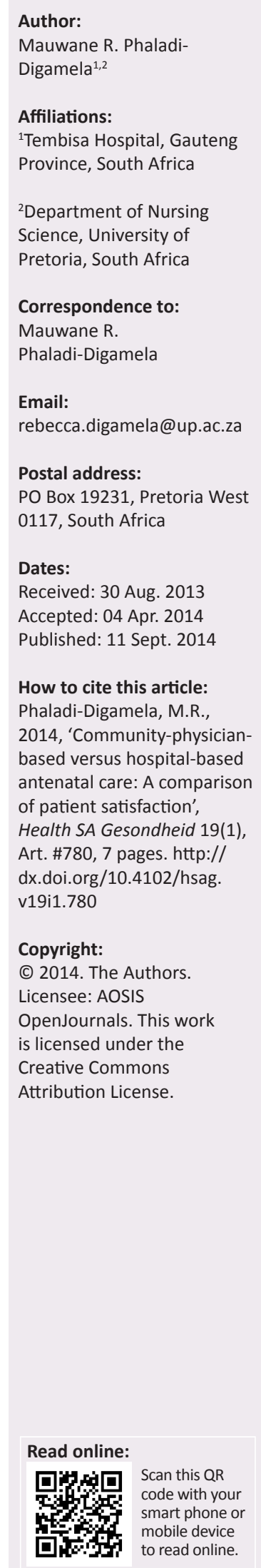

Background: Strategies to meet the healthcare needs of pregnant women are made available throughout antenatal, intra-partum and post-natal periods. These strategies are aimed at reducing perinatal and maternal mortality amongst women who access and utilise healthcare at an early stage. Late visits with irregular antenatal attendance result in failure to adequately use antenatal interventions.

Objectives: This study intended to compare and describe the level of patient satisfaction with antenatal care between two groups of women who received free antenatal care from community private physicians and public midwives.

Methods: A quantitative comparative descriptive design with a Likert-scale measure was used. Sixty women, half from each group, participated in the study. Structured questionnaires with closed-ended response options were used to obtain data.

Results: The midwives' group was less satisfied with antenatal care than the physicians' group, with the former citing long waiting times as contributing to their dissatisfaction with antenatal care.

Conclusion: Addressing long waiting times improves satisfaction with antenatal care. Daily antenatal visits, rather than visits on a specific day, may reduce long waiting times as women's visits are spread over all clinic days. Satisfaction with antenatal care has implications for access to healthcare, resulting in positive pregnancy outcomes.

Agtergrond: Strategieë om in die gesondheidsorgbehoeftes van swanger vroue te voorsien, word dwarsdeur die voorgeboorte, intra-partum en nageboorte periodes beskikbaar gestel. Hierdie strategieë beoog om die perinatale en moederlike sterfstesyfers te verlaag onder vroue wie reeds op 'n vroeë stadium gesondheidsorg benut. Onreëlmatige en laat voorgeboortebesoeke lei daartoe dat voorgeboorte ingrypings nie voldoende benut word nie.

Doelwitte: Hierdie studie het beoog om twee groepe vroue se vlak van tevredenheid met die gratis voorgeboortesorg wat hul by privaat praktisyns uit die gemeenskap en vroedvroue uit die openbare sektor ontvang het, te vergelyk en beskryf.

Metode: 'n Kwantitatiewe vergelykende beskrywende ontwerp met 'n Likert-skaal is gebruik. Sestig vroue, die helfte van elke groep, het aan die studie deelgeneem. Gestruktureerde vraelyste met geslote-vrae opsies is gebruik om die data te verkry.

Resultate: Die praktisyns se groep was meer tevrede met die voorgeboortesorg as die vroedvroue se groep, veral ten opsigte van wagtye.

Gevolgtrekkings: Deur die probleem van wagtye aan te spreek, kan die tevredenheid met voorgeboortesorg verhoog word. Daaglikse voorgeboortesorgbesoeke, eerder as besoeke op spesifieke dae, kan lang wagtye verminder aangesien besoeke dan oor al die kliniekdae versprei word. Tevredenheid met voorgeboortesorg hou implikasies in vir toegang tot gesondheidsorg, wat positiewe swangerskapsuitkomste tot gevolg het.

\section{Introduction}

\section{Literature review}

Patient satisfaction is an important indicator with regard to the evaluation of quality care and is a test that enables health programmes to assess the influence of their services on consumers; for this reason, it can be seen as an integral part of the quality assurance surrounding healthcare delivery (Ghobashi \& Khandekar 2008:326; Ibrahim, Chompikul \& Isaranurug 2008:146). Patients that are satisfied with their care are more likely to use healthcare services adequately and adhere to recommended treatment. However, poor satisfaction with healthcare can lead to poor 
adherence to treatment and, consequently, to poor outcomes (Ibrahim et al. 2008:151).

Antenatal care is a pregnancy-related service which is a component of the maternal health service that is necessary for the identification of complications and danger signs and to provide screening, treatment and education during pregnancy with the aim of improving pregnancy outcomes (Agus \& Horiuchi 2012:8; Hollowell et al. 2009:7). Keeping to the recommended number of antenatal visits provides a beneficial and cost-effective opportunity for women to receive the necessary treatment (Akkerman et al. 2012:7; Anya, Hydara \& Jaiteh 2008:2). Attending maternal healthcare services, such as antenatal care, offers a boost in maternal health which is necessary in order to enhance the health of infants (Abou-Zahr \& Wardlaw 2003:1).

Public antenatal care is provided by registered nurses or midwives on specific days at some designated primary healthcare facilities in South Africa (Bradshaw et al. 2008:14). Bradshaw et al. (2008:6) further state that a requirement of antenatal care is that it should be of a high quality and must be available when needed. Despite the mentioned requirement, the aforementioned authors note that antenatal care is often unavailable, as it is provided on specific days only. It is therefore less accessible to pregnant women who might only be free on days when no antenatal service is available. Inability to provide antenatal care on a daily-basis might pose a challenge regarding missing antenatal attendance for employed pregnant women who are only available to access healthcare services after working office hours or over weekends when the clinic is closed. Specific days assigned for antenatal care furthermore result in overcrowding and long waiting times which are common practice in South Africa (National Department of Health 2011:4). Antenatal care provided at community physician's healthcare rooms was provided every day, except Sundays. Based on this difference in availability of services, it was deemed necessary to explore the quality of antenatal care from the patients' perspective in order to compare the levels of satisfaction with care received from community private physicians and the care received from government midwives in a particular township with elevated perinatal mortality.

According to Openshaw, Bomela and Pretlove (2011:1), antenatal services are found everywhere in South Africa, but maternal and perinatal mortality remain a challenge (Sibeko \& Moodley 2008:17a). At least 92\% of pregnant women in South Africa attend their first antenatal care visit during their third trimester of pregnancy (World Health Organization 2011:30). This high rate $(92 \%)$ of visiting antenatal care for the first time late in pregnancy and only attending one antenatal visit during the whole pregnancy is a problem, as opportunities for accessing antenatal interventions are missed. This is aggravated by irregular visits and the pregnant women's inability to comply with the recommended number of antenatal visits. The recommended number of antenatal visits during pregnancy in South Africa is four. It is preferred that pregnant women should commence antenatal care between eight and 12 weeks, but before 16 weeks' gestation (Myer \& Harrison 2003:268). It is during these visits that pregnant women receive the minimum antenatal care required. However, patients also wait for hours to obtain files, to see the nurse or the doctor and then wait further long hours to get medicines (National Department of Health 2011:4).

Visiting antenatal care facilities late in the third trimester is a serious challenge as any existing or new health problem resulting from pregnancy could be in an advanced stage. This makes antenatal interventions less effective, resulting in maternal and perinatal complications and mortalities. The country may be unable to meet its set target of achieving the Millennium Developmental Goals (MDGs) number four for reducing perinatal mortality, number five for reducing maternal death and number six for the reduction of human immunodeficiency virus (HIV) infection by 2015 (Zeidan, Idris \& Bhairy 2011:590).

Quality antenatal care should be a cornerstone for women to safeguard their health outcomes (Hoque, Hoque \& Kader 2008:66a). In fact, quality antenatal care is considered to be a focused strategy for the reduction of maternal death in any country interested in achieving MDG number four (Zeidan et al. 2011:590). Quality antenatal care gives women an opportunity to be assessed and screened, provided with treatment and preventive measures and offered health education, advice and counselling (Gross et al. 2010:2; Lincetto et al. 2006:55). Furthermore, pregnant women arrange their birth plan and receive further preventive interventions such as immunisation against tetanus infection and HIV testing and counselling in order to prevent mother-to-child transmission of HIV infection for improved pregnancy outcomes. In order to benefit from quality antenatal interventions, women need to visit antenatal care facilities early in their first trimester of pregnancy. It is against this background that increasing use of quality antenatal care is a major strategy for improved positive pregnancy outcomes (Abdel Maqsood, Oweis \& Hasna 2012:141). The late first visit to antenatal care in the third trimester of pregnancy often results in missed opportunities to access minimum quality care that might allow for the prevention or treatment of problems early in pregnancy. In view of the abovementioned situation, namely that many South African women visit antenatal care facilities late in their third trimester of pregnancy, clarity was sought regarding pregnant women's satisfaction with antenatal care.

Openshaw et al. (2011:1) state that inadequate antenatal care because of late bookings and failure to comply with recommended antenatal visits contributes to avoidable perinatal deaths and maternal complications in South Africa. Some of the antenatal complications lead to the death of these women. In 2008, 260 perinatal and children's deaths occurred daily (Bradshaw et al. 2008:4) and in the period 2008-2010 
the maternal mortality rates increased to 172.22/100 000 (Department of Health 2012:iv). Many of these deaths could be prevented if pregnant women accept responsibility for their health through early initiation and frequent attendance of antenatal care (Department of Health 2012:62).

Private obstetricians and midwives provide antenatal healthcare services at a financial cost to pregnant women and also help to reduce overcrowding in public institutions. However, one needs to have access to a medical aid scheme or enough funds to sustain the recommended number of quality antenatal visits. Quality antenatal care using private-public partnership to measure satisfaction levels with care was therefore deemed necessary because of the high prevalence of perinatal mortality in the area covered by this study. In addition, pregnant women often presented to the labour ward for intra-partum care with evidence that antenatal care had been provided. In certain instances, some pregnant women with known obstetric complication(s) of previous pregnancy presented in the labour ward with severe pregnancy-related problems such as severe pre-eclampsia or eclampsia. According to the Department of Health (2012:20), about 4867 maternal deaths were entered into the country's database and of those, 16.5\% lacked antenatal care and 7\% received infrequent antenatal care in South Africa.

Abdel Maqsood et al. (2012:141) state that women who are satisfied with their antenatal care are more likely to adhere to the recommended number of antenatal visits. Satisfaction levels had to be established in areas providing free antenatal care in order to ascertain levels of quality of antenatal care from the perspective of pregnant women. There was little evidence regarding satisfaction with antenatal care in the area identified for this study. The researcher often observed pregnant women reporting for intra-partum care having had infrequent and/or having lacked antenatal care. Furthermore, on the first visit to the antenatal clinic, only the first 200 women received care. These women arrived as early as 5 am to wait for antenatal care that commenced three hours later. Although most women arrived early, after number 200 all the remaining women were turned away without initiating antenatal care. Although some pregnant women were turned back at this antenatal clinic, some of them presented at the labour ward and sometimes reported a lack of foetal movements. On assessment, the heart rate often could not be traced and healthcare personnel blamed this on a lack of antenatal care.

\section{Problem statement}

The researcher is a midwife who practised in the labour ward of the selected facility for this study and she observed that the antenatal clinic at the facility was often overcrowded with pregnant women who came for their first antenatal visit. Only the first 200 women presenting each day for their first visit received antenatal care and the clinic space was inadequate for such a big number. In the study by Openshaw et al. (2011:5), it was found that overcrowding in antenatal clinics was also experienced by a Pretoria group of pregnant women who had less than the required number of antenatal care visits. In the study on which this article is based, the pregnant women often arrived early in the morning to queue for antenatal care that commenced hours later. These women waited a long time before being examined and they were subjected to a number of routine investigations being performed on them without adequate explanation. Furthermore, these women were often given educational talks that focused mainly on the danger signs of pregnancy.

In 2001, the Research Unit for Maternal and Infant Health Care Strategies of the Medical Research Council (MRC) looked into the partnership between the private sector (physician-based) and public sector (clinic/hospital midwifebased) antenatal care in Tembisa Township in Gauteng. The local hospital in the township and the surrounding clinics experienced increased perinatal mortality at 50/1000 and that prompted the private-public partnerships. The initial partnership (with the MRC and private physicians) was measuring the gestational age at initiation of antenatal care and the quality antenatal care by auditing of antenatal cards. This study focused on measuring satisfaction with antenatal care provided by community private physicians and public midwives in the local hospital and surrounding clinics of the township. Antenatal care was free for women in the two groups. Women who visited participating community private physicians' consulting rooms and had their pregnancy confirmed, were referred by the physicians to the selected hospital for routine special investigations, as these are done for all pregnant women in government antenatal care. The physicians further requested these women to continue their antenatal care at their consulting rooms for the duration of pregnancy. In addition, these women were informed that the birth of their baby should take place at the local hospital because community private physicians did not perform intra-partum care.

The Research Unit for Maternal and Infant Health Care Strategies, under Protocol No: IPA 23 95/2000, was approved to look into the vision of private-public sector cooperation in community obstetrics, specifically looking at the antenatal care of the indigent population of Tembisa (Mokhondo 2011). Specific physicians within Tembisa Township took part in the project. The researcher was responsible for interviewing patients with regard to their satisfaction with the antenatal care they received from private community physicians and from public clinics and/or hospital in the Tembisa Township.

The hypothesis was that the use of physician-based antenatal care for women who choose it could substantially improve their level of satisfaction with the care they receive and that they would consequently keep to the recommended number of antenatal visits. Satisfaction is a person's feeling of pleasure resulting from comparing products or perceived performance or outcome of a product or service in relation to his or her expectations (Rashmi \& Vijaykumar 2010:110). Satisfaction with care could be a major determinant of the utilisation of healthcare, irrespective of the provider of that 
service. On the other hand, a lack of satisfaction with care could turn out to be a major demotivating factor with regard to the use of healthcare services (Jafari et al. 2010:52). In this study, the focus was on satisfaction with free antenatal care provided by private community physicians and public midwives.

\section{Aim of the study}

The aim of this study was to compare and describe patient satisfaction with antenatal care between two groups: the first group of women received antenatal care from private community physicians whilst the second group of women received their antenatal care from midwives at the public hospital and surrounding clinics. It was critical to understand the pregnant women's satisfaction with antenatal care in order to enhance the considerations underpinning healthcare use by pregnant women.

\section{Research methods and design Design}

A quantitative descriptive comparative study design was followed in order to obtain data regarding satisfaction levels with antenatal care between community private physicians and public midwives. A descriptive design was used to compare satisfaction levels with antenatal care (Burns \& Grove 2009:236). To reach the aim of the study, structured interviews were conducted with 60 participants (30 women from community private physicians and 30 women from midwives) in order to describe their level of satisfaction with antenatal care. To gather data about their antenatal experiences, interviews were conducted in the postnatal ward following delivery on day one, before the women were discharged from the hospital.

\section{Study population}

Women who received free antenatal care from private community physicians as well as those who attended antenatal care provided by midwives at the hospital and surrounding clinics within the township were recruited to participate in the study. These women gave birth at the selected public hospital labour ward situated in a township of the Gauteng province in South Africa. All participants came from the township and informal settlements; the latter included shack dwellings. Their economic status was low, with most (97\%) of the doctors' group and (93\%) of the midwives' group being unemployed and relying on government healthcare. Further, only 3\% in both groups had a monthly income of more than R4400.00. The majority of participants had education up to high school level. The respondents spoke various official South African languages, namely Sepedi, Setswana, isiZulu and isiXhosa; the researcher was able to communicate in all those languages.

\section{Sampling method}

Purposive sampling was used for participants who attended antenatal care at the community physicians' private healthcare settings. Because of the smaller size of this group, every patient who was found at the postnatal ward each day of the interview was recruited into the study. Random sampling was used for patients who attended public antenatal care provided by midwives at the hospital and surrounding clinics. These patients were selected by approaching every second patient in a cubicle of the postnatal ward. The antenatal card was checked for booking status and, if a patient met the criteria, she was recruited into the study and informed consent was obtained after the purpose of the study was explained. Individual interviews took place in a private room in the postnatal ward for both groups.

\section{Inclusion criteria}

Only women who had attended antenatal care twice or more and had their antenatal card with them were eligible to take part in the study because they would have interacted with healthcare professionals during pregnancy.

\section{Data collection method}

The researcher obtained informal consent from the unit manager each day of data collection and was allowed to use a private room in the postnatal ward for interviews. An existing questionnaire was used to collect data. The questionnaire was obtained from the MRC unit at Kalafong Hospital because patient satisfaction as an indicator of quality antenatal care was of interest to the department. The questionnaire was previously used on a similar Afrikaansspeaking population of postnatal women. The instrument was translated from Afrikaans into English by a professional translator so that it could be used by a non-Afrikaansspeaking person. The questionnaire was used as an interview guide because most study participants had a low literacy level with insufficient education to complete postal or self-administered questionnaires. A pilot test was done to find out if the data collection instrument was feasible (Rees 2011:38) and this test was conducted with five participants who were excluded from the major study.

A total of 60 respondents were interviewed. Half were from the community private physicians' group and another half were from the midwives' group. Interviews were conducted in each participant's language (Sepedi, Setswana, isiZulu and isiXhosa), which the researcher was able to speak. Each interview lasted for 30 minutes.

\section{Data analysis}

Patient responses to Likert-scale items were coded with numerical values. A score of five represented the most satisfaction and a score of one represented dissatisfaction with antenatal care (Desaulniers Miller et al. 2010:45). 'Agree'/'strongly agree' and 'disagree'/'strongly disagree' were combined as similar responses in order to make final responses. In instances where women agreed/agreed strongly or disagreed/disagreed strongly, items were collapsed to represent 'agree' or 'disagree' in the final 
report in this study. Data were transferred to a spreadsheet from all questionnaires and was processed using Statistical Analysis System (SAS) software version 9.0 (SAS Institute, North Carolina State University 2004) in order to generate comparative statistics between satisfaction levels with antenatal care between the two groups.

\section{Ethical considerations}

Ethics is concerned with the protection of humans in research to ensure the absence or minimisation of harm to respondents (Creswell \& Plano Clark 2011:113; Schneider et al. 2007:81). Ethical clearance was obtained from the Research Ethics Committee of the University of Pretoria (Ref No: IPA 23 95/2000). Permission was also sought from the chief executive officer of the hospital where the study was conducted. Informed consent was obtained from the respondents before the data were collected; a written consent form was handed out and the purpose of the study was explained. The right of patients to refuse participation without fear of intimidation or victimisation was also described before they were requested to sign the form for data collection.

Respondents were informed that there would be no remuneration for taking part in the study. The researcher's contact details were given to respondents on the information leaflet so that they could contact the researcher for further clarity about the study. Furthermore, all respondents were assured that their information would be treated with respect and confidentiality and they were informed that the results of the study would be published in an accredited scholarly journal.

\section{Validity and reliability}

Validity refers to whether one can draw meaningful inferences from scores on a particular instrument, whilst reliability refers to whether scores for items on an instrument are consistent and stable over time. This includes test administration and scoring (Maree 2007:297). A pilot study was conducted to ensure the reliability of the instrument (Burns \& Grove 2009:44). The initial questionnaire was prepared in Afrikaans and was then translated into English by a professional translator. The instrument was tested through a pilot study to determine its feasibility and the time needed for each interview. The population who used the initial instrument had similar characteristics, such as low educational and low income levels. In addition, the instrument was validated and it was ready to be used. To ensure internal consistency, items that measured finances and continuity of care were removed since the participants had free antenatal care and continuity of care is not practised in public healthcare facilities.

\section{Results \\ Socio-demographic profile}

The total number of respondents in the study was 60 , with the doctors' and midwives' groups each comprising 30 respondents. The doctors' group had attended free antenatal care at private community physicians' healthcare rooms and the midwives' group had attended their free care at either the public hospital or the surrounding clinics in Tembisa, in the Ekurhuleni Region of Gauteng. Women from both groups had a low family income and most used public healthcare facilities when not pregnant. The groups lived in townships, informal settlements and shacks.

\section{Obstetric profile}

Information regarding previous pregnancies was included in this study because women with such a background may have certain expectations regarding healthcare service. Women who had gone through previous pregnancies were satisfied with the care received from both groups, which means that previous antenatal use may not be a factor for satisfaction with current services.

Women using public antenatal care complained about long waiting times. The results regarding combined 'agree/ strongly agree' and 'disagree/strongly disagree' are shown in Table 1.

\section{Discussion}

The purpose of this study was to compare and describe patient satisfaction with antenatal care between two groups of patients; the first receiving care from private community physicians and the second receiving their care at the hospital and surrounding clinics associated with the hospital. Overall, the women in this study were satisfied with antenatal care, irrespective of the healthcare provider. However, the findings revealed that the doctors' group were 16\% more satisfied than the midwives' group. This finding concurs with findings in the study by Nketiah-Amponsah and Hiemenz (2009:55), in which users of private healthcare services had increased satisfaction (12\% more), with care being compared with those in public healthcare. In their study, Zeidan et al. (2011:594) found that the level of satisfaction with private antenatal care was roughly four times more when compared

TABLE 1: Results of patient satisfaction with antenatal care.

\begin{tabular}{|c|c|c|c|c|}
\hline Item & Doctors' group & $\%$ & Midwives' group & $\%$ \\
\hline I am satisfied with antenatal care & Agree/strongly agree & 93 & Agree/strongly agree & 77 \\
\hline The service was bad & Disagree/strongly disagree & 100 & Disagree/strongly disagree & 70 \\
\hline The doctor and/or sister does not listen to me & Disagree/strongly disagree & 100 & Disagree/strongly disagree & 73 \\
\hline The doctor or the sister did tests without explanation & Disagree/strongly disagree & 93 & Disagree/strongly disagree & 76 \\
\hline The doctor or the sister did his or her best to comfort me & Agree/strongly agree & 100 & Agree/strongly agree & 83 \\
\hline The doctor or the sister explained to me what to expect from my results & Agree strongly agree & 100 & Agree/strongly agree & 84 \\
\hline I had to wait for a long time before the doctor or the sister could see me & Agree/strongly agree & 7 & Agree/strongly agree & 77 \\
\hline
\end{tabular}


against public antenatal care. A significant proportion of the midwives' group cited only long waiting times as being a problem in the current study. The findings regarding long waiting times are similar to the findings of Nwaeze et al. (2013:27). All of the doctors' group were of the view that antenatal care was not bad, whilst $70 \%$ of the midwives' group were of this opinion. Despite the long waiting time at public antenatal facilities, the respondents in this study did not receive bad service.

Dissatisfaction with antenatal care amongst the midwives' group (which was public-based), was attributed to the long waiting times seen in this study. Obamiro (2010:2) confirmed that publicly-funded healthcare facilities have long waiting times, which discourages the early utilisation of healthcare services. In South Africa, long waiting times are exacerbated by the fact that public antenatal care is offered only on specific days, which poses the challenge of overcrowding as many women target those specific days in order to receive care. Rashmi and Vijaykumar (2010:113) concur that long waiting times cause major dissatisfaction amongst the users of healthcare services. Patients in their study indicated that they had opted to use private health services, as waiting times are reduced in those healthcare settings. Consequently, those who cannot afford private healthcare services may delay their visits to government healthcare facilities in order to avoid long waiting times. Not all pregnant women can afford private healthcare in South Africa; that is why maternal healthcare services are free so as to encourage access and use. Reducing waiting times encourages the early utilisation of antenatal care and compliance with the recommended number of antenatal visits. Early access to antenatal care often leads to early access to a broad range of health-promotion and preventive services that promote maternal and child health (Gross et al. 2012:1; Montasser et al. 2012:151).

Since large numbers of pregnant women attend public antenatal facilities, women arrived very early (three hours before the facility opened) in order to book their space for antenatal care that commenced later, during normal office hours. This long waiting time is generally unacceptable to pregnant women during their pregnancy which is why some women opted to report late - in the third trimester of pregnancy - or resorted to irregular antenatal visits. Regular surveys of patient satisfaction in South Africa are done and have to wait a long time before healthcare is received remains a challenge in the country. This challenge is evidenced in circumstances in which patients have died whilst in the queue without being seen by a nurse or a doctor in public healthcare facilities (National Department of Health 2011:4). Reducing waiting times for interventions such as patient assessment remains a priority area for immediate improvement in South Africa (Whittaker et al. 2011:63).

Rashmi and Vijaykumar (2010:111) reported that pregnant women in their study experienced long waiting times as in the study currently under discussion. Some of the women in the study by Rashmi and Vijaykumar missed immunisation sessions on certain days as they could not attend care provided on those days. At least 30 minutes was cited to be an acceptable period for waiting. Most women were satisfied with the time they had spent with either a doctor or a midwife during consultation; that is why pregnant women in the current study still rated the care provided by midwives as being good (see Table 1), with the long waiting times being the only concern.

\section{Limitations of the study}

The sample size was small and only one township was used for the study; therefore, the results may not be generalised. However, the results appear to be congruent with other similar studies, as was mentioned earlier in this report.

\section{Recommendations}

A follow-up research study with a bigger sample size is necessary for the comparison of satisfaction with antenatal care between public and private midwives in order to establish if there is a difference between the two groups. Furthermore, comparison can also be done between townships, allowing for an assessment of satisfaction levels with antenatal care. Provision of adequate physical space at public antenatal facilities, together with supply of extra midwives, will reduce overcrowding and, ultimately, long waiting times will be lowered. A qualitative study to obtain valuable insights into women's perception of antenatal care is necessary. Qualitative exploratory studies can permit one to ascertain the aspects of quality that best determine satisfaction with antenatal care (Oladapo, Iyaniwura \& Sule-Odu 2008:89). It is also important to do a study amongst healthcare providers, as long waiting times do indeed occur in healthcare facilities.

\section{Conclusion}

The purpose of this study was to compare patient satisfaction with antenatal care. Two groups of women participated in the study: the first group received their care from community private physicians and the second group received their care from midwives at the public hospital and surrounding clinics. It was found that those long waiting times at public antenatal care facilities promoted late visits during the third trimester of pregnancy or gave rise to irregular visits to antenatal care facilities. The research provides evidence that this is an area that should be improved on in order to promote the quality of antenatal services in public healthcare facilities in South Africa.

Women expressed their satisfaction with antenatal care despite their displeasure with the long waiting times at government antenatal facilities. It is recommended that waiting times be addressed in order to improve satisfaction levels amongst women using public antenatal services and to encourage early and frequent visits. It is for this reason that the National Department of Health in South Africa has identified 'waiting times to receive care' as being part 
of the six most critical areas for patient-centred care in the country. Additional space with more personnel (midwives) should be provided so as to relieve major overcrowding in public antenatal services. Maternal and perinatal outcomes can improve through early initiation of antenatal care as opportunities for women to benefit from available healthcare services are realised.

In conclusion, adequate availability of antenatal care services may not necessarily mean accessibility and early utilisation by pregnant women unless they are satisfied with the care they receive. Although the experiences of the two groups regarding the antenatal care were not seen to be much different in this study, the midwives' group definitely experienced longer waiting times. Increased physical space and provision of extra midwives during antenatal care for public healthcare facilities will reduce long waiting times, thus satisfying pregnant women. This ought to result in early access to a broad range of preventive and promotion services.

\section{Acknowledgements}

The researcher wishes to express heartfelt appreciation to the patients who participated in this study. Most especially, appreciation goes to Professor S.J.C. van der Walt for unconditional support and guidance throughout the study and Professor R.C. Pattinson for initiating the private-public partnership project with general practitioners in the Tembisa Township. A special thanks to Ella Belcher, the language editor and Ruth Albertyn, the critical reader and all other reviewers for their contribution in this study.

\section{Competing interests}

The author declares that she has no financial or personal relationship(s) which may have inappropriately influenced her in writing this article.

\section{References}

Abdel Maqsood, A.S., Oweis, A.I. \& Hasna, F.S., 2012, 'Differences between patients' expectations and satisfaction with nursing care in a private hospital in
Jordan', International Journal of Nursing Practice 18(2), 140-146. http://dx.doi. Jordan', International Journal of Nursing Pr

Abou-Zahr, C.L. \& Wardlaw, T.M., 2003, Antenatal care in developing countries: Promises, achievements and missed opportunities. An analysis of trends, levels and differentials, 1990-2001, World Health Organization, Geneva.

Agus, Y. \& Horiuchi, S., 2012, 'Factors influencing the use of antenatal care in rural West Sumatra, Indonesia', BMC Pregnancy and Childbirth 12, 9. http://dx.doi. org/10.1186/1471-2393-12-9

Akkerman, D., Cleland, L., Croft, G., Eskuchen, K., Heim, C., Levine, A. et al. Institute for Clinical Systems Improvement, 2012, 'Routine prenatal care', viewed 26 July 2014, from https://www.icsi.org/_asset/13n9y4/Prenatal.pdf

Anya, S.E., Hydara, A. \& Jaiteh, L.E., 2008, 'Antenatal care in the Gambia: missed opportunity for information, education and communication', BMC Pregnancy and Childbirth 8, 9. http://dx.doi.org/10.1186/1471-2393-8-9

Bradshaw, D., Chopra, M., Kerber, K., Lawn, J., Moodley, J., Pattinson, R. et al., 2008, Every death counts: Saving the lives of mothers, babies and children in South Africa, Department of Health Republic of South Africa, MRC South Africa, University of Pretoria, Faculty of Health Sciences, Save the Children and UNICEF.

Burns, N. \& Grove, S.K., 2009, Understanding nursing research: Building and evidence-based practice, 5th edn., Elsevier Saunders, Maryland Heights, MO

Creswell, J.W. \& Plano Clark, V.L., 2011, Designing and conducting mixed methods research, 2 nd edn., Sage Publications, Thousand Oaks, CA.
Department of Health, 2012, Saving Mothers 2008-2010, Fifth report on confidential enquiries into maternal deaths in South Africa, Health Systems Trust, Durban.

Desaulniers Miller, M.C., Montplaisir, L.M., Offerdahl, E.G., Cheng, F.C. \& Ketterling, G.L., 2010, 'Comparison of views of the nature of science between natural science and nonscience majors,' CBE Life Sciences Education 9(1), 45-54. http://dx.doi. org/10.1187/cbe.09-05-0029

Ghobashi, M. \& Khandekar, R., 2008, 'Satisfaction among expectant mothers with antenatal care services in the Musandam Region of Oman', Sultan Qaboos University Medical Journal 8(3), 325-332.

Gross, K., Alba, S., Glass, T. R., Armstrong Schellenberg, J.A. \& Obrist, B., 2012, 'Timing of antenatal care for adolescent and adult pregnant women in south-eastern Tanzania', BMC Pregnancy and Childbirth 12, 16. http://dx.doi.org/10.1186/ 1471-2393-12-16

Hollowell, J., Kurinczuk, J.J., Oakley, L., Brocklehurst, P. \& Gray, R., 2009, A systemic review of the effectiveness of antenatal care programmes to reduce infant mortality and its major causes in socially disadvantaged and vulnerable women. Final report, National Perinatal Epidemiology Unit, University of Oxford.

Hoque, M., Hoque, E. \& Kader, S.B., 2008, 'Audit of antenatal care in a rural district of KZN, South Africa', South African Family Practice 50(3), 66.

Ibrahim, A., Chompikul, J. \& Isaranurug, S., 2008, 'Patient satisfaction with health services at the outpatient department of Indira Gandhi Memorial Hospital, Male' Maldives', Journal of Public Health and Development 6(1), 144-152.

Jafari, F., Eftekhar, H., Mohammad, K. \& Fotouhi., A., 2010, 'Does group prenatal care affect satisfaction and prenatal care utilization in Iranian pregnant women?', Iranian Journal of Public Health 39(2), 52-62.

Lincetto, O., Mothebesoane-Anoh, S., Gomez, P. \& Munjanja, S., 2006, 'Antenatal care', in L. Joy \& K. Kate (eds.), Opportunities for Africa's newborns: Practical data policy and programmatic support for newborn care in Africa, pp. 51-62, World Health Organization, on behalf of The Partnership for Maternal Newborn and Child Health.

Maree, K., 2007, First steps in research, Van Schaik Publishers, Pretoria.

Mokhondo, R., 2001, Protocol No: IPA 23 95/2000. Vision of private-public sector co-operation in community obstetrics: the effect of involving private practitioners on the quality of antenatal care of the indigent population of Tembisa, Research Unit for Maternal and Infant Health Care Strategies, Pretoria.

Montasser, N.A.E.M., Helal, R.M., Megahed, W.M., Amin, S.K., Saad, A.M., Ibrahim, T.R. et al., 2012, 'Egyptian Women's Satisfaction and Perception of antenatal care', International Journal of Tropical Disease \& Health 2(2), 145-156. http://dx.doi. org/10.9734/IJTDH/2012/1312

Myer, L. \& Harrison, A., 2003, 'Why do women seek antenatal care late? Perspectives from rural South Africa', Journal of Midwifery \& Women's Health 48(4), 268-272. http://dx.doi.org/10.1016/S1526-9523(02)00421-X

National Department of Health, 2011, Towards quality care for patients': Nationa core standards for health establishments in South Africa, $\mathrm{NDOH}$, Tshwane, South Africa.

Nketiah-Amponsah, E. \& Hiemenz, U., 2009, 'Determinants of consumer satisfaction of health care in Ghana: Does choice of health care provider matter?', Global Journal of Health Science 1(2), 50-61. http://dx.doi.org/10.5539/gjhs.v1n2p50

Nwaeze, I.L., Enabor, O.O., Oluwasola, T.A.O. \& Aimakhu, C.O., 2013, 'Perception and satisfaction with quality of antenatal care services among pregnant women at the University College Hospital, Ibadan, Nigeria, Annals of Ibadan Postgraduate Medicine 11(1), 22-28.

Obamiro, J.K., 2010, 'Queuing theory and patient satisfaction: An overview of terminology and application in ante-natal care unit', Bulletin Vol. LXII No. 1/2010, Economic Sciences Series, Petroleum-Gas University of Ploiesti, Romania.

Oladapo, O.T., Iyaniwura, C.A. \& Sule-Odu, A.O., 2008, 'Quality of antenatal services at the primary care level in southwest Nigeria', African Journal of Reproductive Health 12(3), 71-92.

Openshaw, M.R., Bomela, H.N. \& Pretlove, S., 2011, 'An evaluation of the timing and use of healthcare during pregnancy in Birmingham, UK and Pretoria, South Africa', ISRN Obstetrics and Gynecology 2011, 6 pages. http://dx.doi. org/10.5402/2011/364243

Rashmi \& Vijaykumar, B., 2010, 'Client satisfaction in rural India for primary health care - a tool for quality assessment', Al Ameen Journal of Medical Sciences 3(2), 109-114.

Rees, C., 2011, Introduction to research for midwives, 3rd edn., Churchill Livingstone, Elsevier, Oxford.

Schneider, Z., Whitehead, D., Elliott, D., Lobiondo-Wood, G. \& Haber, J., 2007, Nursing \& midwifery research: Methods and critical appraisal for evidenced-based practice, 3rd edn., Elsevier, Mosby, Saunders, Philadelphia, PA.

Sibeko, S. \& Moodley, J., 2008, 'Healthcare attendance patterns by pregnant women in Durban, South Africa', South African Family Practice 48(10), 17.

Whittaker, S., Shaw, C., Spieker, N. \& Linegar, A., 2011, 'Quality standards for healthcare establishments in South Africa' South African Health Review 59-67.

World Health Organization, 2011, World Health Statistics 2011, viewed 04 August 2014, from http://www.who.int/whosis/whostat/EN_WHS2011_Full.pdf

Zeidan, Z.A., Idris, A.M. \& Bhairy, N.M., 2011, 'Satisfaction among pregnant women towards antenatal care in public and private care clinics in Khartoum', Khartoum Medical Journal 4(2), 590-595. 